\title{
IMPROVMENT OF CLOTHES FIT FOR DIFFERENT FEMALE BODIES
}

\author{
OIga V. Surikova, Victor E. Kuzmichev, Galina I. Surikova \\ Department of Clothing Design, Textile Institute, Ivanovo State Polytechnic University, 21, Sheremetev Ave., Ivanovo, Russian Federation, \\ e-mail: ola_surikova@mail.ru \\ tel.: +79203514801 , fax.: +74932412108
}

\begin{abstract}
:
The factors influencing for fit and suit of women's clothing have been studied. The main reason of misfit is the nonconformity between the front and back width of pattern block, the corresponding body sizes taken across the hipline, and the textile materials properties. To predict the behavior of textile fabrics in real clothes including the shear deformation and wrinkles appearing, the special test and device have been designed. The developed method of pattern block making includes the test of clothes proportionality based on the female bodies sizes, pattern block indexes, and textile fabrics properties. Features of "figure-clothes" systems in-cluding the vertical designing lines, styles, volume of clothes, ease allowance and its distribution between the back, armhole, and front of the pattern blocks were taken into consideration. Recommendations in terms of selecting the proper design of style for different sizes of female bodies have been made.
\end{abstract}

\section{Keywords:}

female body, body sizes, pattern block, clothes, proportionality, fitting, textile fabric.

\section{Introduction}

Clothing is an external cover for human body that follows a contours of body and forms new shape around one depending from construction, decorative details and textile fabric properties. The indicator of design and tailoring is the fit, which is determined by the proportionality that should exist between the body sizes, on one side, and the pattern block parameters, on the other side. The absence of proportionality is the main reason of misfit, especially for women in big sizes.

Proportionality is the proper ratio between the clothing sizes and the body sizes. Prediction of fit is a difficult problem because of variety of shapes of the female bodies. Many authors studied the problem of fit [1-9]. Aldrich [1] and Joseph-Armstrong [4] analyzed the anthropometrical specific body features that influenced on the pattern block parameters and the reasons of defects of clothes and the ways of its elimination. Some methods are suggested to predict the fit during a pattern block drawing and before real try-on $[5,6]$. These methods allow to test the clothes proportionality in the longitudinal direction, that is, to avoid the defects in stature and shoulder girdle areas. However, the peculiarities of female body morphology, especially for large-sized women are concerned, necessitate providing the proportionality of the pattern blocks at hip area not only in the lengthwise but also in the crosswise direction. According to Karen LaBat and DeLong [7], the most clothes fitting problems take place at hip area.

Problem of misfit appearance could be divided into two parts: first part is related to the method of pattern block making and second part is related to textile materials properties taken into the consideration before block drafting. Main methods of pattern block making are starting to draw the bodice from bust line and divide it between front, armhole, and back using the corresponding body sizes such as "back width" and "front width." But this approach is suitable only for bust level but not for hip especially for the females with the special morphology [10].

The proportionality of pattern block across hipline might be obtained by using the parts of hip girth divided between the front and the back. If the body has the hip girth bigger them the bust girth, the pattern block should be increased on the hip level; if the bust girth bigger than the hip girth, the pattern block became narrow on the hip line. The proportionality between the body and the pattern block can be checked by the following equation:

$$
L P=0,5 H G+E_{\mathrm{HG}}
$$

where $L P$ is the width across hipline on the pattern block, $\mathrm{cm}$;

$H G$ is the hip girth, cm;

$E_{\mathrm{HG}}$ is the ease allowance added to $H G$ along hipline, depending from the style, $\mathrm{cm}$.

Figure 1 shows the pattern blocks of two type of dress with seven and three vertical lines, the places of hip width measuring, and the equations for proportionality checking.

$L P$ is the sum of two values as back $a$ and front $b$ for the simplest design (Fig. 1b). If the dress has more seams, the total sum should include $c, d$, e, and $f$ (Fig. 1a). 


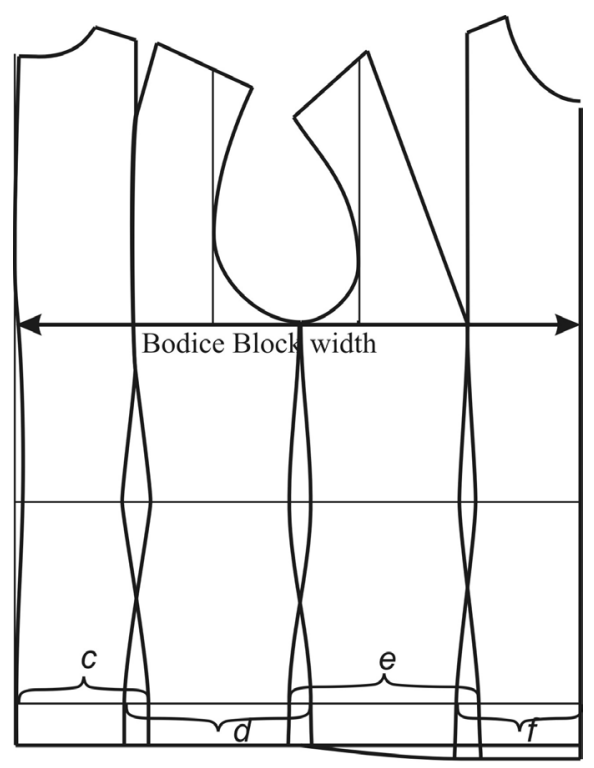

$L P=c+d+e+f$

(a)

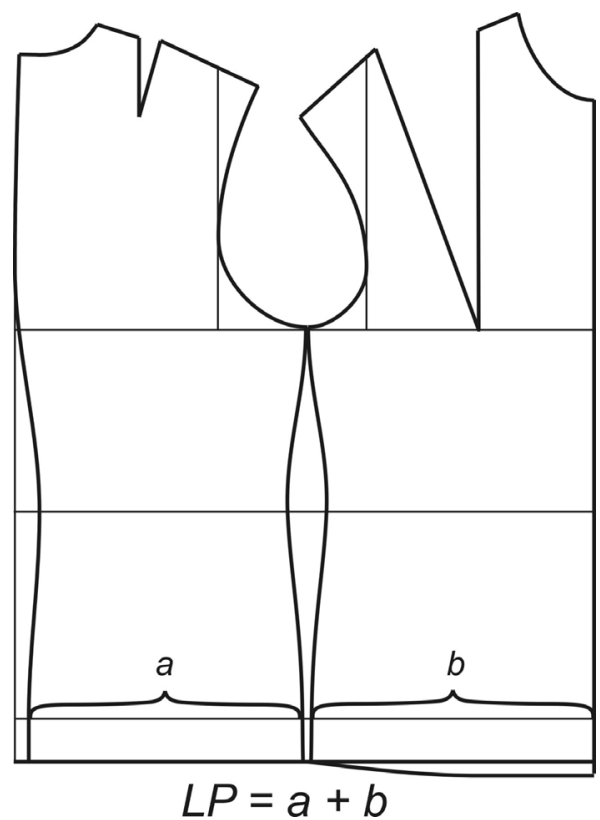

(b)

Figure 1. Scheme of pattern blocks measuring across the hipline when dress has seven (a) and three (b) vertical seams

However, the equations from Fig. 1 couldn't explain the wrinkles or folds appearing on the hip level of real dress (Fig. 2).

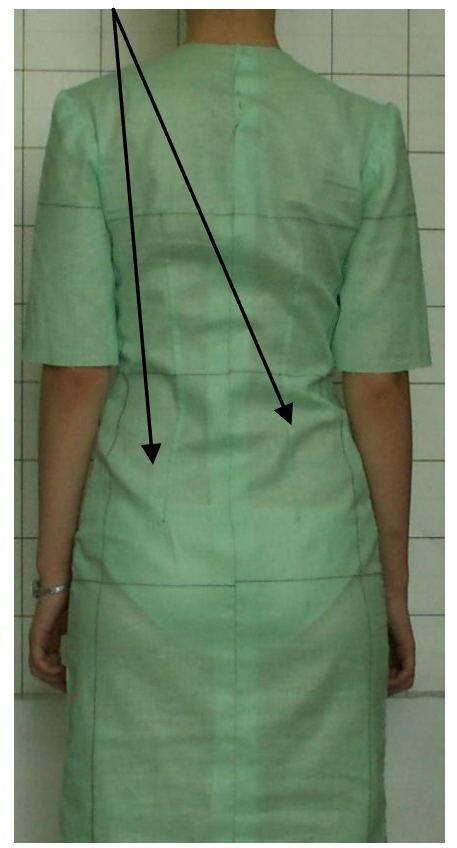

Figure 2. Folds and wrinkles located between the waist and the hip and caused by the absence of the proportionality between the clothes and the body across hip

The emergence of these folds may be caused by the lack of back width across the buttocks and(or) the front width in abdomen [10]. If there is the lack of the width in one site of the dress, in the other part, it may be excessively large. Owing to different stress conditions, the clothes parts across the hipline will be displaced from the area of excessive width to the area of the lack of width, that is, the material will be sheared crosswise. Transverse shear causes the material distortion, resulting in the formation of folds and deterioration of external appearance. As was established before in our exploration, $49 \%$ of women were likely to have a misfit clothes, whose bust girth is more than $116 \mathrm{~cm}$ or whose hip girth is more than $6 \mathrm{~cm}$ bigger than the bust girth.

So, if we know the hip girth on the back, the front, and under armhole, we could predict the folds appearing in real clothes for each body type.

However, the other reason of wrinkles and folds appearing are related to textile materials properties. The problem of fabric distortion and development of folds in the clothes has been studied [11-13]. However, until the present time, the criteria haven't been established for allowable transverse shear value at which smooth appearance is maintained in clothes made of different fabrics.

Thus, the improvement of pattern block making with due regard to the fabric properties will allow to get the good fitting clothes.

It is obvious that there are two conditions that allow to avoid the defects caused by oblique folds:

if the size of clothes along hipline is bigger (or equal) than the hip girth [14];

if the fabric admits the possibility of transverse shear to some definite point without the appearance of folds even though the width of clothing sites at hip is less than body circumference by a value of permissible lack of clothing site width $d$. Value $d$ is determined by the allowable value of fabric transverse shear coefficient at which the fabric remains smooth.

The research is focused on the decision of the following problems:

development of experimental method which can help to test the proportionality of clothes made of different types of fabrics 
at hipline area.

optimization of clothes design for the bodies of different sizes, which will ensure a good fit across hipline.

\section{Objects of study}

Female bodies: Hundred and thirty bodies with bust girth from 84 to $136 \mathrm{~cm}$ and height from 158 to $176 \mathrm{~cm}$.

Woven materials. Sixteen fabrics that are most widely used for manufacture of women's clothes.

All fabrics were previously divided into five groups in accordance with its formability [15]. Formability have been characterized by the bias angle between wrap and weft $(\beta)$ and by tensile strain $(e)$ under limited elongation in diagonal direction. Formability was determined with the help of tensile machine IR 50743 (Russia) in accordance with GOST 3813-72 [16]. Samples have been cut in bias direction $\left(45^{\circ}\right)$ and tested under load force $2 \mathrm{daN}$. The range of bias angle was from $10^{\circ}$ to $38^{\circ}$, and tensile strain value was from $0 \%$ to $21.5 \%$.

Clothes shape: Five hundred and eighteen designs of female clothes have had the following differences:

- the ease to half bust girth was from 2 to $10 \mathrm{~cm}$, the ease to half waist girth was from 2 to $23 \mathrm{~cm}$, the ease to half hip girth was from 1 to $16,5 \mathrm{~cm}$;

- dresses styles: tightly fitted, small-volume, semi-fitted, slightly fitted, full, extra-full,

- pattern blocks with different number and location of vertical seams.

Method of pattern block making: We used the more popular methods that are producing the good fit of clothes [17-20].

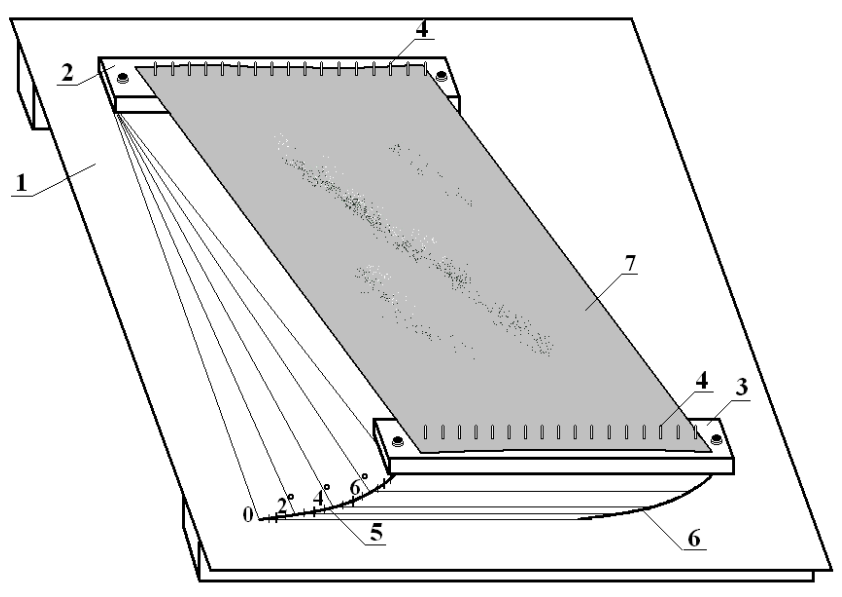

a clothes" (b)

\section{Experimental studies on justification of the amount of permissible lack of the clothes parts width across hipline}

To explore the conditions of sample shearing and wrinkles appearing, a special device has been designed. The testbed has the platform 1 located vertically with the fixing elements stationary 2 and movable 3 fastened on it (Fig. 3a).

Three rectangular samples sized $35 \mathrm{~cm}$ (warp) $\times 20 \mathrm{~cm}$ (weft) were cut out of the fabric. The sample length $35 \mathrm{~cm}$ is equal to the average distance between the bust and the hip adopted for standard female bodies $(33-37 \mathrm{~cm})$. The sample was fixed by elements 2 and 3 , and then the movable clip was moved along the circle arch 6 . During the movement the sample length did not change, and the fabric was sheared without stretching. At a certain moment of the shearing, an fold appeared on the sample surface during the movement of element 3 . Results of testing are including the indexes $g$ and $h$. Using the scale 5 , the angle $g$ of the fabric shearing was established and the value $h$ can be calculated by using the following formula (Fig. 3b):

$$
h=35 \sin \gamma
$$

where $\quad h$ is the tested value, $\mathrm{cm} ; 35$ is the sample length, $\mathrm{cm}$; and $\gamma$ is an angle of shear, degree.

As the length of sample corresponded to the length of the potential zone of distortion in the clothes, the permissible lack of the clothing site width is equal to the allowable fabric transverse shear: $d=h$.

The indexes of shearing $-\gamma, d$, and $h-$ for chosen fabrics are shown in Table 1.

Table 1 shows the relations existing between the formability and shearing indexes. When the formability have increased, the shear angle and values of permissible lack of the clothing site width also increased without the formation of

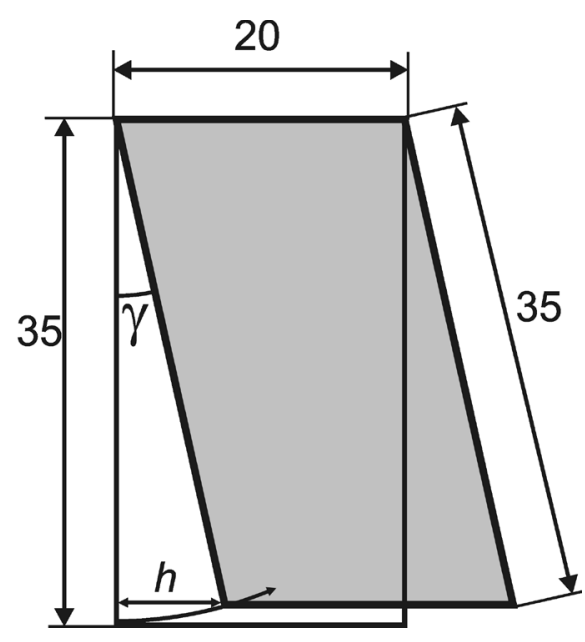

b 
Table 1. Properties of textile materials

\begin{tabular}{|c|c|c|c|c|c|c|c|}
\hline \multirow[b]{2}{*}{ Fabric } & \multicolumn{3}{|c|}{ Formability indicators [15] } & \multirow[b]{2}{*}{ Fiber content } & \multicolumn{3}{|c|}{ Indexes measured } \\
\hline & Formability & $\begin{array}{c}\text { Threads } \\
\text { bias angle } \beta \text {, } \\
\text { degrees }\end{array}$ & Strain $\varepsilon, \%$ & & $\begin{array}{l}\text { Shear } \\
\text { angle } \gamma \text {, } \\
\text { degree }\end{array}$ & $\begin{array}{c}\text { Transverse } \\
\text { shear h, } \\
\text { cm }\end{array}$ & $\begin{array}{l}\text { Permissible lack } \\
\text { of the clothing site } \\
\text { width } \mathrm{d}, \mathrm{cm}\end{array}$ \\
\hline 1 & Very low & $10-15$ & $0-9,5$ & Various & 0 & 0 & 0 \\
\hline 2 & Satisfactory & $16-22$ & $9.5-12.5$ & Polyester & $0-1.5$ & Under 1 & Under 1 \\
\hline 3 & Medium & $23-30$ & $12.5-15.5$ & $\begin{array}{l}\text { Cotton + } \\
\text { polyester }\end{array}$ & $1.6-3$ & $1.1-2$ & $1.1-2$ \\
\hline 4 & High & $31-34$ & $15.5-18.5$ & $\begin{array}{c}\text { Wool + } \\
\text { polyester }\end{array}$ & $3.1-4.5$ & $2.1-3$ & $2.1-3$ \\
\hline 5 & Very high & $35-38$ & $18.5-21.5$ & Wool & $4.6-6$ & $3.1-4$ & $3.1-4$ \\
\hline
\end{tabular}

folds. For the clothes made of different fabrics, the values of permissible lack of the width across hipline may be from 0 to $4 \mathrm{~cm}$. For example, the fabrics with medium formability allow to design the clothes with permissible lack of the width from 1.1 to $2 \mathrm{~cm}$ without visible folds and wrinkles. If this value is bigger than $2 \mathrm{~cm}$, the clothes will have the undesirable folds and wrinkles.

So, new results about the possible difference between the body and clothes sizes open the original way of pattern block checking in accordance with the body morphology and textile fabrics properties measured in special conditions that are very close to real wearing process.

\section{Method of proportionality testing across hipline of pattern block}

To divide the hipline of the pattern block into the front, the side, and the back parts, it is necessary to draw vertical lines tangential to the armhole on the front and the back and then to make measurements of back $L P b$, side $L P s$, and front $L P f$. Figure $4 a$ shows the scheme of these lines drawing and measuring. Back part is located between the back fold (or seam) and the vertical line moving from the narrowest point of back width; side part is located between the latest mentioned line and the line moving from the narrowest point of front width; front part is located between the latest mentioned line and front fold.

In this research, the techniques are suggested to determine the width in pattern blocks used in made-to-measure (MtM) and ready-to-wear clothes.

1) MtM clothes. For MtM clothes, the body sizes mentioned can be taken directly from the consumer. To divide the hip line into front, side, and back sites, we should put an elastic ribbon around the hip girth (Fig. 4b).
Using a plumb bobs, we projected the front and back armpit points to the elastic ribbon and then divided the hip girth into back $L F b$, side $L F s$, and front $L F f$.

2) Ready-to-wear clothes. For these kinds of clothes, we created the special equations for calculating the front, side, and back width of hip girth. For standard body types, the equations are suggested to calculate the width of parts at hip area:

$$
\begin{aligned}
& \text { Back } \quad L F b=0,175 H G ; \\
& \text { Side } \quad L F s=0,12 H G ; \\
& \text { Front } \quad L F f=0,205 H G .
\end{aligned}
$$

Figure $5 c$ shows the variant of cross-section with the distribution between front, side, and back.

To check the proportionality of pattern block along hip line, we should do the following steps.

The width of the sites measured on the pattern block are compared to the corresponding body sites. The site on the pattern block will be sufficient to cover the corresponding body site if its size is equal to or less than the body site by permissible lack of width $d$ :

$$
L P_{i} \geq L F_{i}-d
$$

where $L P_{i}$ is the width of the pattern block site across hipline, $\mathrm{cm}$;

$L F_{i}$ is the width of the body site across hipline, $\mathrm{cm}$;

$d$ is the permissible lack of the clothing site width across hipline, cm (see Table 1).

If the condition (6) isn't acceptable, the pattern block might be correct by increasing the following sites (Fig. 5): 


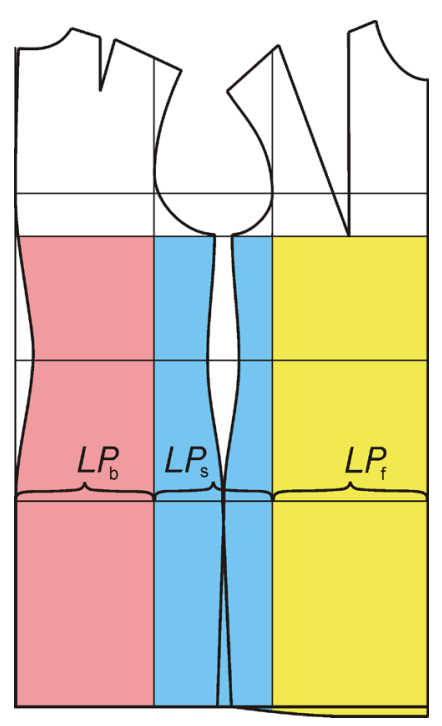

b front, side, and back (c)

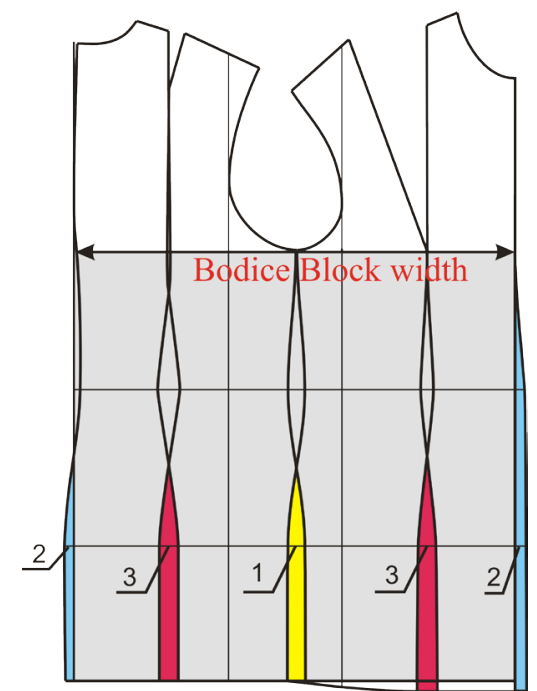

Figure 5. Areas of hipline expansion at the pattern block

1) back and front can be increased by means of sections 2 or additional lines with sections 3 ;

2) side site can be increased by means of section 1 .

For example, the pattern block of dress designed from the fabric with permissible lack of the clothing site width $d=1 \mathrm{~cm}$ and for the body with known sizes has the following indexes:

\begin{tabular}{|c|c|c|c|}
\hline \multirow{2}{*}{$\begin{array}{c}\text { Place of } \\
\text { measurement }\end{array}$} & \multicolumn{3}{|c|}{ Width, cm } \\
\hline & Back & Side & Front \\
\hline Width of hip, cm & 21.1 & 16 & 27.9 \\
\hline $\begin{array}{l}\text { Hip line of pattern } \\
\text { block, } \mathrm{cm}\end{array}$ & 21.3 & 20.1 & 26.5 \\
\hline $\begin{array}{l}\text { Difference between } \\
\text { pattern block and } \\
\text { body, cm }\end{array}$ & $\begin{array}{c}21.3- \\
21.1= \\
-0.2\end{array}$ & $\begin{array}{l}20.1-16 \\
=4.1\end{array}$ & $\begin{array}{c}26.5- \\
27.9= \\
-1.4\end{array}$ \\
\hline
\end{tabular}

Half of hip girth is $65 \mathrm{~cm}$; the width along hip line of pattern block is $67.9 \mathrm{~cm}$. So, the ease to hip girth is $2.9 \mathrm{~cm}$, it means that the pattern block has enough width. But the pattern front is smaller than the body front, so the pattern front should be increased to a minimum of $0.4 \mathrm{~cm}$. This dress hasn't back seam, so the additional seam might be added to create the sections 3 with the width of $0.4 \mathrm{~cm}$. Side part should be decreased in $0.4 \mathrm{~cm}$.

\section{Styles that allow to avoid the misfit}

Five hundred and eighteen pattern blocks of women's clothes (dresses, jackets, denim coats) in different styles and sizes were made. They differed in the number of lengthwise cutting lines and styles. Dresses in tightly fitted, semi-fitted, slightly fitted, full (loosely), extra full (extra loosely), and A styles were analyzed.

The basic fit criteria of pattern block was equation (6).

All styles of women clothes with regard to the number of vertical cutting lines were analyzed (Table 2). We chosen four types of clothes style. The volume of dress was characterized by the ease allowances across the bust, waist, and hip lines (Table 3).

As the ease allowances at the waist and hip lines depend on the shape volume specified in Table 3 , only ease allowance across bust line will be used for further characterization of the clothing form.

For all pattern blocks, an uniform distribution of ease have been adopted across the bust line in back, armhole, and front:

Ease to back width

$$
E_{B W}=0,2 E_{B G}
$$

Ease to armhole width

$$
E_{\mathrm{AHW}}=0,7 E_{\mathrm{BG}}
$$

Ease to front width

$$
E_{\mathrm{FW}}=0,1 E_{\mathrm{BG}} .
$$


Table 2. Variants of pattern blocks

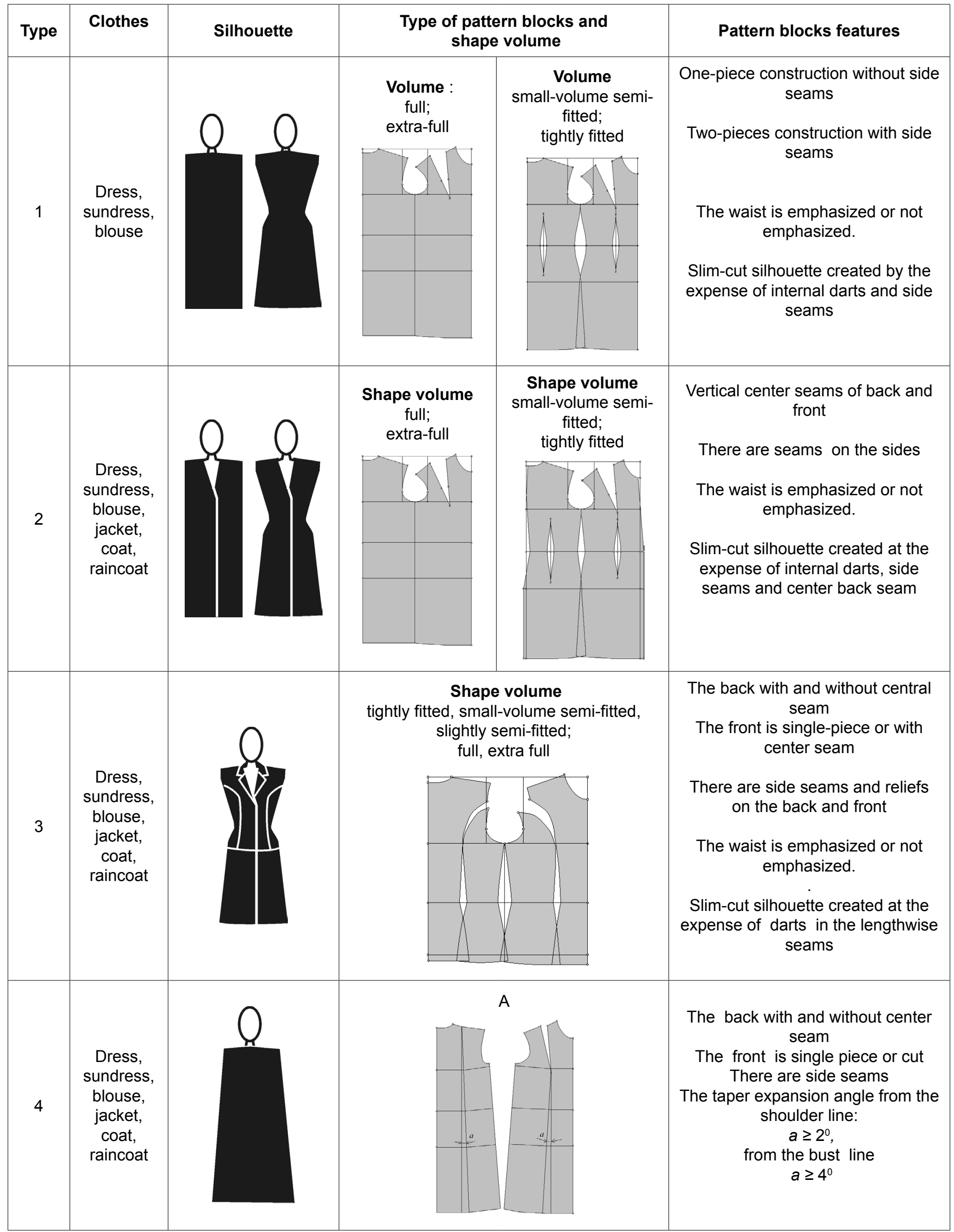


Table 3. Parameters of the pattern blocks studied

\begin{tabular}{|c|c|c|c|c|c|c|c|c|c|}
\hline \multirow{2}{*}{ Style } & \multicolumn{3}{|c|}{$\begin{array}{l}\text { Ease to half bust girth }\left(E_{\mathrm{BG}}\right), \\
\mathrm{cm}\end{array}$} & \multicolumn{3}{|c|}{$\begin{array}{l}\text { Ease to half waist girth }\left(E_{\mathrm{wG}}\right), \\
\qquad \mathrm{cm}\end{array}$} & \multicolumn{3}{|c|}{$\begin{array}{l}\text { Ease to half hip girth }\left(E_{\mathrm{HG}}\right), \\
\mathrm{cm}\end{array}$} \\
\hline & Dress & Jacket & Coat & Dress & Jacket & Coat & Dress & Jacket & Coat \\
\hline Tightly filled & $2-3$ & $3-4$ & $5-6$ & $2-3$ & $3-4$ & $5-6$ & $1-2$ & $2-3$ & $3-4$ \\
\hline semi-fitted & $4-5$ & $5-6$ & $7-8$ & $4-5$ & $5-6$ & $7-8$ & 3 & 4 & 5 \\
\hline Slightly fitted & $6-8$ & $7-8$ & $9-10$ & $6-9$ & $7-10$ & $9-12$ & 3 & 4 & 5 \\
\hline Full & $7-8$ & 9 & 11 & $8-10$ & $11-13$ & $13-15$ & 4 & 4,5 & 5,5 \\
\hline Extra-full & 9 & $10-11$ & $12-13$ & $12,5-21$ & $13,5-24$ & $15,5-26$ & 5 & 6 & 7 \\
\hline$A$ & $2-7$ & $3-11$ & $5-13$ & $3-17$ & $4-21$ & $6-23$ & $4-10,5$ & $5-14,5$ & $7-16,5$ \\
\hline
\end{tabular}

Pattern block of fourth type has the back with $2^{\circ}$ taper expansion from the shoulder seam and the front with $4^{\circ}$ taper expansion from the bust line.

The blocks were developed using different pattern cutting systems [17-20] for Russian standard women's bodies (height is $164 \mathrm{~cm}$, bust girth are $84-136 \mathrm{~cm}$ ). For all bodies, the hip girth is bigger than the bust girth in $8 \mathrm{~cm}$, which is consistent with the Russian body sizes system [21]. This morphology, when the hip girth is bigger, the bust girth in $8 \mathrm{~cm}$ is the characteristic of women's bodies in other countries as well, for example, in the United States for figures of 55+ category [22], the quantity of such women's body types is $44 \%$; in Germany, $100 \%$; in Italy, $15,4 \%$; and in Japan, $44 \%$.

For bodies with the large hip girth and small bust girth, it is necessary to add the expansion across the hipline. Different pattern blocks have different possibilities for adding expansion at hipline area. The expansion at hipline may got: first style, in the side seam (Fig. 5); second, in the side seams and across the center front and center back (Fig. 5); third style, in the side seam, in the centre seams of the front and the back, and in the lengthwise relief seams of the front and back (Fig. 5); fourth style, by the ease across hipline.

The acceptability of the styles was estimated from testing proportionality at separate hipline parts (4). The amount of permissible lack of width in the hipline sites was taken as 2 $\mathrm{cm}$, which corresponds to fabrics possessing average forming ability (see Table 1).

Using "Grazia" CAD (Ukraine), the pattern blocks of all styles with the eases specified in Table 3 were drafted for the whole range of bodies sizes. For each size and each style, the width across hipline were calculated and compared to the corresponding width of the body; using equation (6), the proportionality was tested.

The hip girth width were calculated by equations (3-5).

The applicability of different styles is shown in Table 4.

Table 4. Variants of acceptable style

\begin{tabular}{|c|c|c|c|c|c|c|c|c|c|c|c|c|c|c|c|c|c|c|c|}
\hline \multirow{2}{*}{ Type } & \multirow{2}{*}{ Style } & \multicolumn{3}{|c|}{ Ease to bust girth $E_{\mathrm{BG}}, \mathbf{c m}$} & \multicolumn{15}{|c|}{ Bust girth BG, cm } \\
\hline & & dress & jacket & coat & 84 & 88 & 92 & 96 & 100 & 104 & 108 & 112 & 116 & 120 & 12 & 12 & & 132 & 136 \\
\hline \multirow{8}{*}{1} & \multirow{2}{*}{ Tightly fitted } & 2 & - & - & & & & & & & & & & & & & & & \\
\hline & & 3 & - & - & & & & & & & & & & & & & & & \\
\hline & \multirow{2}{*}{ Semi-fitted } & 4 & - & - & & & & & & & & & & & & & & & \\
\hline & & 5 & - & - & & & & & & & & & & & & & & & \\
\hline & \multirow{2}{*}{ Slightly fitted } & 6 & - & - & & & & & & & & & & & & & & & \\
\hline & & 7 & - & - & & & & & & & & & & & & & & & \\
\hline & Full & 8 & - & - & & & & & & & & & & & & & & & \\
\hline & Extra-full & 9 & - & - & & & & & & & & & & & & & & & \\
\hline \multirow{9}{*}{2} & \multirow{2}{*}{ Tightly fitted } & 2 & 3 & 5 & & & & & & & & & & & & & & & \\
\hline & & 3 & 4 & 6 & & & & & & & & & & & & & & & \\
\hline & \multirow{2}{*}{$\begin{array}{c}\text { Small-volume, } \\
\text { semi-fitted }\end{array}$} & 4 & 5 & 7 & & & & & & & & & & & & & & & \\
\hline & & 5 & 6 & 8 & & & & & & & & & & & & & & & \\
\hline & \multirow{2}{*}{ Slightly fitted } & 6 & 7 & 9 & & & & & & & & & & & & & & & \\
\hline & & 7 & 8 & 10 & & & & & & & & & & & & & & & \\
\hline & Full & 8 & 9 & 11 & & & & & & & & & & & & & & & \\
\hline & \multirow{2}{*}{ Extra-full } & & 10 & 12 & & & & & & & & & & & & & & & \\
\hline & & & 11 & 13 & & & & & & & & & & & & & & & \\
\hline 3 & $\begin{array}{l}\text { Any degree of } \\
\text { fitting }\end{array}$ & $2-8$ & $3-11$ & $5-13$ & & & & & & & & & & & & & & & \\
\hline 4 & A & $2-7$ & $3-11$ & $5-13$ & & & & & & & & & & & & & & & \\
\hline
\end{tabular}

Note: the acceptable variants are highlighted in color 
The increasing $E_{\mathrm{BG}}$ will ensure proportionality condition for a wider range of body sizes.

The greater is the number of lengthwise cutting lines, the wider is the applicability range of the pattern for bodies in different sizes.

First style will suffer from maximum applicability limitations in the entire range of the body size variants.

Second style will exhibit the wider range of acceptability. Along cutting lines, the clothes is additionally expanded to compensate the projected areas of buttock and abdomen. That is why the pattern blocks of the second type are acceptable for $62.8 \%$ of standard bodies and not acceptable for ones whose bust girth is more than $128 \mathrm{~cm}$.

Third style can be adopted for practically all types of bodies.

Fourth style will be able to ensure the proportionality across hipline for any body size and has no limitations in application. A-style has the widest range of the applicability as compared to other styles. Clothes having taper expansion of $4^{\circ}$ and more from the bust level will ensure the proportionality across hipline for all body sizes.

Increasing the ease allowance does not allow to enhance the acceptability of any type of styles for bodies in huge size. Table 5 illustrates how the ease allowance at the front area influences their acceptability for first style.

For example, if $E_{\mathrm{BG}}=3 \mathrm{~cm}$ and its share in the front is $E_{\mathrm{FW}}=$ $0.1 E_{\mathrm{BG}}=0.3 \mathrm{~cm}$, the proportionality will be achieved within the size range $84-100$. If the ease allowance is increased from $0.1 E_{\mathrm{BG}}$ to $0.2 E_{\mathrm{BG}}$, the good variants will include the sizes 104 and 108. With the increasing of ease allowance in the front, the width of the front site across hipline is also increased, and consequently, for a larger number of sizes, the proportionality for the hipline area is satisfied.

For $B G=128 \mathrm{~cm}$ and larger sizes, all styles are involving redistribution of ease allowance to achieve the proportionality; in this case, it is necessary to apply other construction solutions.

Applicable variants are presented in Table 6 for second style $\left(E_{\mathrm{BG}}=5 \mathrm{~cm}, E_{\mathrm{WG}}=5 \mathrm{~cm}, E_{\mathrm{HG}}=3 \mathrm{~cm} ; E_{\mathrm{BG}}\right.$ divided between the front, back, and armhole as $0.1: 0.7: 0.2$ ).

It is advisable to use the identified application fields of different variants of pattern blocks and fabric shear coefficients at the stage of choosing a construction solution for the clothes model with regard to a specific body size, shape volume of the clothes, and type of the fabric.

\section{Conclusions}

Clothes proportionality occurring in real system "body-clothes" and influencing on the clothes fit, folds, and wrinkles appearing on the surface of clothes was studied from different points of view such as special textile materials properties, new body sizes extracted from hip girth, pattern block construction, and clothes style. Results of our research will help avoid mentioned defects in clothes caused by the lack of the proportionality across hipline and transverse shear of textile fabrics.

Original device that allows to reconstruct the behavior of textile fabrics in real clothes including the shear deformation and wrinkles appearing have been designed.

Table 5. The influence of ease on first style acceptability

\begin{tabular}{|c|c|c|c|c|c|c|c|c|c|c|c|c|c|c|}
\hline \multirow{2}{*}{$\begin{array}{l}\text { Ease to } \\
\text { bust girth } \\
E_{\mathrm{BG}}, \mathrm{cm}\end{array}$} & \multicolumn{14}{|c|}{ Bust girth BG, cm } \\
\hline & め & $\infty$ & สั & ๘ே & 웅 & 음 & $\stackrel{\infty}{\circ}$ & $\stackrel{N}{\leftarrow}$ & $\stackrel{\oplus}{\tau}$ & 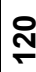 & $\stackrel{\mathbb{N}}{\stackrel{Z}{*}}$ & $\stackrel{\infty}{\sim}$ & $\mathfrak{2}$ & $\stackrel{m}{\sim}$ \\
\hline 2 & & & & & & & & & & & & & & \\
\hline 3 & & & & & & & & & & & & & & \\
\hline 4 & & & & & & & & & & & & & & \\
\hline 5 & & & & & & & & & & & & & & \\
\hline 6 & & & & & & & & & & & & & & \\
\hline 7 & & & & & & & & & & & & & & \\
\hline 8 & & & & & & & & & & & & & & \\
\hline 9 & & & & & & & & & & & & & & \\
\hline
\end{tabular}

-acceptable variant when the ease allowance is $E_{\mathrm{FW}}=0,1 E_{\mathrm{BG}}$

- widening the range of acceptable variants of the style by increasing the ease allowance

$E_{\mathrm{FW}}=0,2 E_{\mathrm{BG}}$

- unacceptable variant

Table 6. The influence of permissible lack of width for second style

\begin{tabular}{|c|c|c|c|c|c|c|c|c|c|c|c|c|c|c|}
\hline \multirow{2}{*}{$\begin{array}{l}\text { Permissible lack of } \\
\text { clothes width, } d, c m\end{array}$} & \multicolumn{14}{|c|}{ Bust girth BG, cm } \\
\hline & 84 & 88 & 92 & 96 & 100 & 104 & 108 & 112 & 116 & 120 & 124 & 128 & 132 & 136 \\
\hline \multicolumn{15}{|l|}{0} \\
\hline \multicolumn{15}{|l|}{$0,1-1$} \\
\hline \multicolumn{15}{|l|}{$1,1-2$} \\
\hline \multicolumn{15}{|l|}{$2,1-3$} \\
\hline $3,1-4$ & & & & & & & & & & & & & & \\
\hline
\end{tabular}


New method of pattern block making including the complex consideration of the female bodies sizes, pattern block parameters, and textile fabrics properties was developed. Features of "body-clothes" systems including the vertical designing lines, styles, volume of clothes, ease allowance, and its distribution between the back, armhole, and front of the pattern blocks were taken into new method algorithm.

New method for testing proportionality of the clothes can be applicable for different types of styles, pattern blocks, and various body sizes.

New techniques are suggested to determine in MtM and readyto-wear clothes.

Future exploration will include the creation of universal method of pattern block making which can be used directly in CAD, design the clothes in different styles for any types of female bodies.

\section{References}

[1] Aldrich W. (2004). Metric Pattern Cutting. (4th ed.). Oxford (England). Blackwell Publishing Ltd. (Oxford).

[2] Beazley A.(1997). Size and fit: Procedures in undertaking a survey of body measurements. Journal of Fashion Marketing and Management, 2(1), 55-85.

[3] Goldsberry E. et al.(1996). Women 55 Years and Older: site II. Overall Satisfaction and Dissatisfaction with the Fit of Ready-to-Wear, Clothing and Textiles Research Journal, 14(2), 121-132.

[4]. Joseph-Armstrong H.(2010). Patternmaking for Fashion Design. (5 ed.). Los Angeles (USA). Prentice Hall (Los Angeles).

[5] Koblyakova E.B. (1984). Basics of designing the rational apparel sizes and shapes. Moscow (Russia Federation). Light and food industry (Moscow).

[6] Kuzmichev V.; et al.(2011). System analysis of Pattern Block. Ivanovo (Russia Federation). ISTA (Ivanovo).

[7] LaBat K. L., DeLong M.(1990). Body Cathexis and Satisfaction with Fit of Apparel. Clothing and Textiles Research Journal, 8(2), 43-48.
[8 ] Guo M., Kuzmichev V., Adolphe D. (2015). Human friendly design of virtual system "Female body - dress". AUTEX Research Journal, (15)1, 19-29.

[9] Guo M., Kuzmichev V. (2013). Pressure and comfort perception in the system "female body-dress". AUTEX Research Journal, 13(3), 71-78.

[10] Surikova G.I. et al.(2006). Intellectual pattern cutting of female apparel in CAD "Grazia". Sewing industry, 3.

[11] Aldrich W. (2012).Fabrics and Pattern Cutting. Chichester (England). John Wiley \& Sons Inc (Chichester).

[12] Collier B. et al.(1989). Effects of Interfacing Type on Shear And Drape Behavior of Apparel Fabrics. Clothing and Textiles Research Journal, 7(3), 51-56.

[13] Robson D.; Long C.(2000). Drape Analysis using Imaging Techniques. Clothing and Textiles Research Journal, 18(1), 1-8.

[14] Patent № 2478323 RU A41H3/00 3/06 (2013). Pattern for pattern block diagnostics / Surikova G.I., Surikova O.V., Kuzmichev V.E. Published 10/04/2013.

[15] Gushchina K.G., Belyaeva S.A., Komandrikova E.J. et al.(1984). Performance characteristics of clothing materials and methods to estimate their quality. Moscow (Russia Federation). Light and food industry(Moscow).

[16] GOST 3813-72 (1972). Cloths textile and products. Methods of tensile characteristics testing.

[17]Common Metric Method Pattern Design (1988). Basic Blocks. Vol. 2.Moscow (Russia Federation). CSDITEllegprom (Moscow).

[18] Yanchevskaya E.A. (2005). Pattern Cutting. Moscow (Russia Federation) Academia (Moscow).

[19] Martinova A.I., Andreeva N.A. (2002). Pattern Cutting. Moscow(Russia Federation). MSALI (Moscow).

[20] Rogov P.I., Konopalceva N.M.(2004). Pattern Cutting for individual Figures. Moscow (Russia Federation). Academia (Moscow).

[21] Standard table of body measurements for women's patterns and apparel. (2003). Moscow (Russia Federation). CNIISHP (Moscow).

[22] ASTM (American Society for Testing and Materials). (1994). D 5586- 94: Standard table of body measurements for women aged 55 and older. New York (USA). American National Standards Institute (New York). 